\title{
Aspectos fisiológicos e bioclimáticos de caprinos nas regiões semiáridas
}

$\underline{\text { Marieta Maria Martins Vieira }}^{1}$, Francisca Mirlanda Vasconcelos Furtado ${ }^{2}$, Magno José Duarte ${\underline{\text { Cândido }^{3}}}^{3}$, José Antônio Delfino Barbosa Filho ${ }^{4}$, Ana Clara Rodrigues Cavalcante ${ }^{5}$, João $\underline{\text { Avelar Magalhães }}^{6}$, Newton de Lucena Costa ${ }^{7}$

${ }^{I}$ Zootecnista, D.Sc. Prof. do Instituto Federal do Ceará. Umirim, CE.

${ }^{2}$, Zootecnista, D.Sc. Fortaleza, CE.

${ }^{3}$ Eng. Agrônomo, D.Sc., Prof. da UFC. Fortaleza, CE

${ }^{4}$ Eng. Agrícola, D.Sc., Prof. da UFC. Fortaleza, CE

${ }^{5}$ Zootecnista, D.Sc., Pesquisador da Embrapa Caprinos e Ovinos. Sobral, CE.

${ }^{6}$ Méd. Vet., D.Sc., Pesquisador da Embrapa Meio-Norte. Parnaíba, PI.

${ }^{7}$ Eng. Agrônomo, D.Sc., Embrapa Roraima. Boa Vista, RR.

*Autor para correspondência, E-mail: marietammv@yahoo.com.br

RESUMO. A caprinocultura apresenta importante papel econômico-social para a região Nordeste, por suprir as populações de baixa renda de proteína de valor biológico. A região possui o maior rebanho caprino do Brasil, resultante da adaptação destes animais às condições climáticas locais. As diferentes respostas do animal às peculiaridades de cada região são determinantes no sucesso da atividade pela adequação do sistema produtivo às características do ambiente e ao potencial produtivo dos animais. Nesta revisão serão abordados alguns aspectos fisiológicos e bioclimáticos da caprinocultura nas condições semiáridas.

Palavras chave: bioclimatologia, equilibro térmico, ruminantes

\section{Physiological and bioclimatic aspects of goats in semi-arid regions}

\begin{abstract}
The goat provides important economic and social role in the Northeast, by supplying the low-income populations of protein biological value. The region has the largest goat herd in Brazil, resulting from the adaptation of these animals to local climatic conditions. The different responses of the animal to the peculiarities of each region are key to the success of the activity by adapting the production system to the characteristics of the environment and the productive potential of animals. In this review we discuss some aspects of the physiological and bioclimatic the goat farming in semi-arid conditions.
\end{abstract}

Keywords: bioclimatology, thermal equilibrium,, ruminants

\section{Introdução}

A caprinocultura apresenta importante papel econômico-social para a região Nordeste, por suprir as populações de baixa renda de proteína de valor biológico. As condições ambientais da região - clima, solo e vegetação - favoreceram a surgimento de animais rústicos, embora de baixa produtividade, adaptados a sobreviver em condições precárias e em períodos de seca.
Por outro lado, além das variáveis climáticas, os sistemas de produção dependem dos objetivos propostos e das prioridades de investimentos, como: alimentação, genética e manejo (Wander \& Martins, 2008). Os principais modelos de sistemas de produção são classificados em: extensivo (quando há a criação de animais não especializados para a produção leiteira, mantidos em pastagens nativas, tendo rendimento da atividade atrelado à fertilidade natural da terra à 
produção sazonal das pastagens, consequentemente, baixos índices produtivos), intensivo a pasto (quando há a criação de animais especializados para produção leiteira ou mestiça, mantida em pastagens cultivadas sob lotação rotacionada, podendo haver suplementação volumosa e/ou concentrada em determinadas épocas do ano), semi-intensivo (quando há a criação de animais especializados para a produção de leite ou mestiços, mantidos em áreas restritas ou galpões com disponibilidade de volumosos e concentrados e, posteriormente mantidos em pastagens cultivadas nas demais horas subsequentes) e intensivo confinado (quando há a criação de animais de raças especializadas mantidos em áreas restritas ou galpões com disponibilidade de volumosos e concentrados de qualidade, permitindo altos índices produtivos).

A adoção de novos modelos de produção pode causar impacto no bem estar animal. Segundo
McInerney (2004) em sua proposição da relação entre a produtividade e o bem estar dos animais de produção, ocorre diminuição no grau de bem estar animal quando há aumento da produtividade em demasia (Gráfico 1).

Esta relação sugere que modelos com baixos índices produtivos, tenham sua produção elevada devido a uma melhoria no manejo (nutricional, sanitário, de instalações, entre outros) ocasionando aumento no grau de bem estar animal (espaço entre A e B). À medida que os modelos de sistemas de produção se intensificam, ocorrem aumentos adicionais de produtividade em detrimento do bem estar animal, ocasionando exploração do potencial biológico do animal. A partir de determinado ponto (D) o grau de bem estar animal é enquadrado como crueldade. O grau ideal de bem estar de animais de produção para diferentes sociedades provavelmente se acomodará ao redor do ponto C (Gráfico 1).

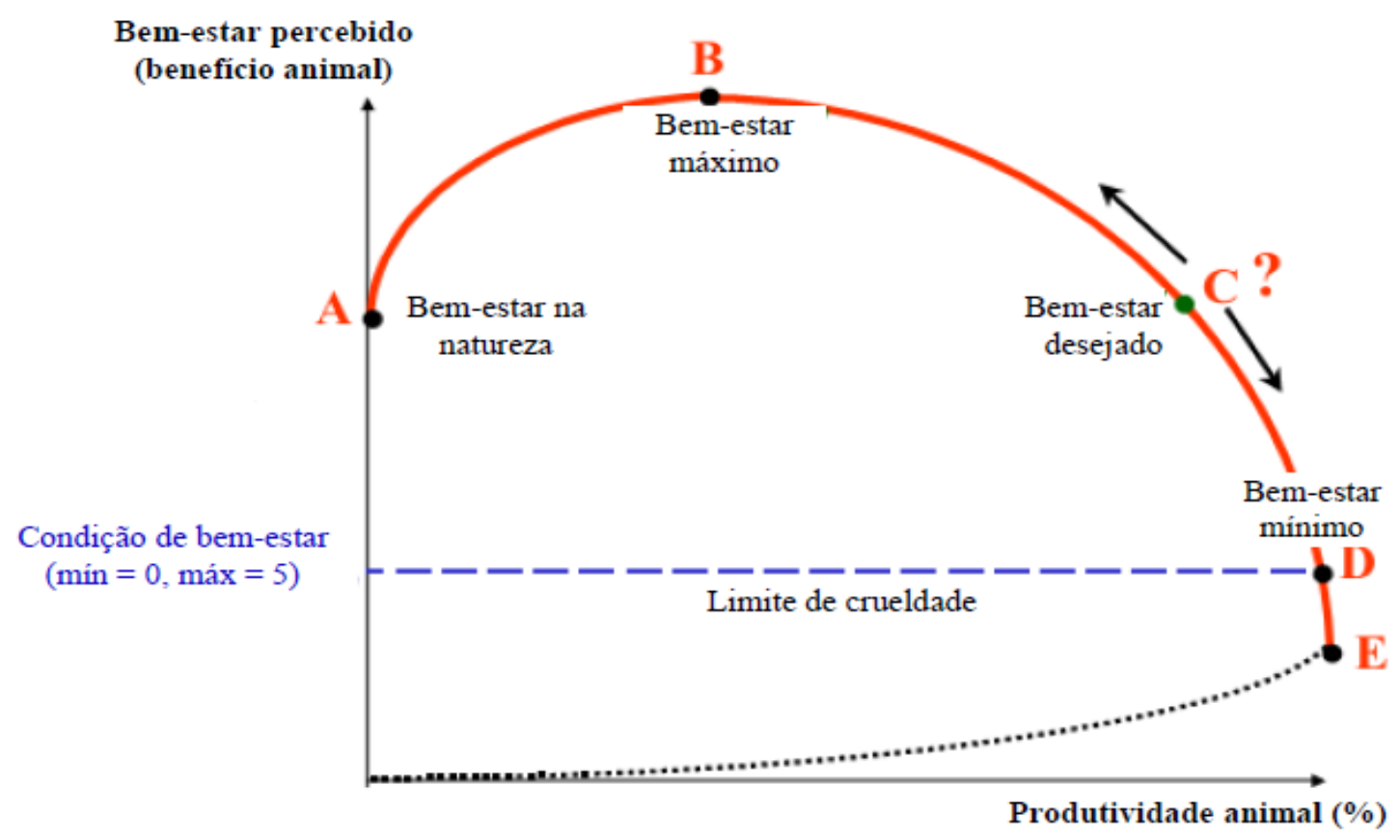

Gráfico 1. Relação entre bem estar animal e produtividade (McInerney, 2004)

\section{Produção em ambientes quentes}

A correta planificação de instalações pecuárias, quer ao nível do condicionamento espacial (arquitetura) quer ao nível do condicionamento ambiental (climatização), é fundamental para que as regras de bem estar animal sejam cumpridas. Estas regras baseiam-se, resumidamente, que o animal deve estar livre de qualquer situação de estresse. Estresse pode ser definido como uma resposta biológica desencadeada quando um indivíduo recebe uma ameaça para a sua homeostase; se essa ameaça se prolonga a permanência em estado de alerta pode conduzir à exaustão. Se um animal se encontra alojado em instalações mal planificadas está frequentemente sujeito a situações de estresse, não só estresse social, mas também estresse 
térmico por frio ou calor excessivo (Cruz et al., 2004).

Para a adequada climatização de uma determinada instalação pecuária é necessário e fundamental dispor de dados meteorológicos do local da instalação (Gabriel Filho et al., 2011). Para esse fim os dados mais importantes são a temperatura ambiente e a umidade relativa do ar. Neste momento, encontram-se disponíveis no mercado estações meteorológicas automáticas, equipadas com sistemas de leitura e armazenamento de dados (por exemplo, data logger's) que permitem coletar, armazenar e transferir a informação pelas sondas e dos sensores que integram essas estações.

Os dados coletados pelas estações automáticas podem ser utilizados para criar sistemas de alerta, os quais permitirão aos produtores ativar as técnicas de manejo de condicionamento ambiental de modo a não expor os seus animais a condições ambientais adversas.

A resposta ao estresse começa quando o sistema nervoso central do animal recebe uma ameaça à homeostase. Nesse momento é desenvolvida uma ação que consiste na combinação de até quatro respostas ou defesas biológicas (Figura 1).

Estas respostas podem ser comportamentais, associadas ao sistema nervoso autônomo, neuroendócrinas e imunológicas. Quando a intensidade do estímulo recebido é pouco acentuada, a resposta inicial é do tipo comportamental. Esta resposta pode não ser apropriada para todas as situações, fazendo com que o animal procure outro tipo de resposta, principalmente quando as ações comportamentais são limitadas ou até impedidas (Moberg, 1999).

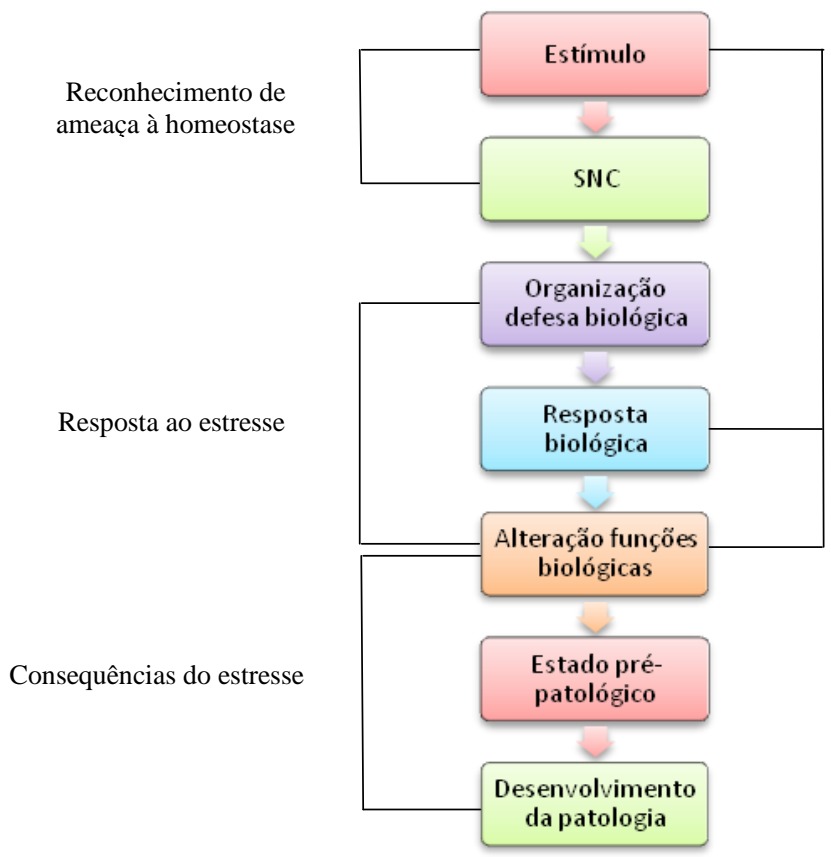

Figura 1 - Modelo de respostas biológicas do animal ao estresse (Moberg, 1999).

A segunda linha de defesa é o sistema nervoso autônomo. Este afeta um diverso número de sistemas biológicos, incluindo os sistemas cardiovascular e gastrointestinal, as glândulas exócrinas e a medula adrenal. Neste caso, as respostas são relativamente rápidas (por exemplo, aumento da frequência cardíaca).

\section{Bem estar animal}

Bem estar animal pode ser definido como uma característica intrínseca dos animais e depende da capacidade de cada indivíduo se adaptar ao seu ambiente e o grau de estresse que esta adaptação causa a este indivíduo, podendo assim o bem estar animal variar entre pobre e muito bom (Broom, 1991). Ou seja, bem estar animal 
envolve as respostas dos organismos às diversas condições do ambiente, para a manutenção de sua homeostase.

O bem estar animal pode ser considerado ainda uma demanda para que um sistema seja defensável eticamente e aceitável socialmente. Outra definição de bem estar utilizada foi estabelecida pela Farm Animal Welfare Council (2008), na Inglaterra, mediante o reconhecimento das cinco liberdades inerentes aos animais: liberdade fisiológica (ausência de fome e sede); liberdade ambiental (edificações adaptadas); liberdade sanitária (ausência de doenças e fraturas); liberdade comportamental (possibilidade de exprimir comportamentos normais); liberdade psicológica (ausência de medo e ansiedade).

O bem estar pode ser medido por métodos científicos e deve ser independente de quaisquer considerações éticas, culturais ou religiosas. São usados vários indicadores para aferir o bem estar de um animal, os mais utilizados são as respostas fisiológicas e comportamentais e a sua condição sanitária (Leeb et al., 2004).

As medidas fisiológicas associadas ao estresse tem sido utilizadas com base em que, se o estresse aumenta, o bem estar diminui. Já os indicadores comportamentais são baseados especialmente na ocorrência de comportamentos anormais ou daqueles que se afastam do comportamento no ambiente natural (Hötzel \& Machado Filho, 2004 ).

Sob condições de estresse térmico, cabras leiteiras ativam seus mecanismos fisiológicos de perda de calor para manterem a sua temperatura corporal média dentro dos termos da homeotermia (Oliveira, 2005; Santos et al., 2005).

Segundo Leite \& Fischer (2011), cabras da raça Saanen confinadas não alteraram seus mecanismos fisiológicos (frequência respiratória, frequência cardíaca e temperatura corporal) e comportamentais (tempo de aproximação, distância de fuga e atitude frente ao isolamento) mediante o número de parições, temperamento (conforme classificação de Lyons, 1989) e produção de leite. Broom \& Fraser (2007) afirmaram que os animais têm a capacidade de se preparar para eventos previsíveis, por meio de mecanismos de feedback que controlam previamente respostas fisiológicas e comportamentais. Se o evento aversivo é previsível, os animais podem se preparar comportamentalmente ou por alterações cerebrais, podendo também se preparar para eventos não aversivos.

\section{Ambiente, termorregulação e adaptação de caprinos}

É de conhecimento geral que os países de economia mais atrasada são normalmente aqueles onde predominam atividades primárias. A agropecuária é uma dessas atividades em que se destaca a geração de emprego e renda e as relações comerciais com as demais atividades (compradores de bens e serviços e fornecedores de insumos para os demais setores). Todavia, há grandes entraves para a maximização da produtividade animal, como: baixa disponibilidade de forragem de boa qualidade, limitada disponibilidade de água, alta temperatura atmosférica e altos níveis de radiação solar direta e indireta (Silanikove, 1992).

Em regiões Semiáridas, onde as condições edafoclimáticas dificultam a exploração agropecuária, a caprinocultura já consolidou sua importância e viabilidade, podendo ser praticada por pequenos e médios produtores e quando bem manejada é uma das poucas atividades sustentáveis nesta região, do ponto de vista ambiental, econômico e social.

As diferentes respostas do animal às peculiaridades de cada região são determinantes no sucesso da atividade pela adequação do sistema produtivo às características do ambiente e ao potencial produtivo dos animais. $\mathrm{O}$ sucesso de um sistema de criação depende, entre outros fatores, da escolha de raças que sejam adaptadas às condições climáticas da região (Monty Junior et al., 1991).

Os critérios de tolerância e adaptação dos animais são determinados por medidas fisiológicas como: frequência respiratória, frequência dos batimentos cardíacos e temperatura corporal (Abi Saab \& Sleiman, 1995).

Os caprinos, assim como outros mamíferos, são animais homeotérmicos (tem a capacidade de controlar a temperatura interna do corpo), embora este mecanismo seja eficaz quando a temperatura ambiente está dentro de certos limites, próximas às das condições de conforto do animal (Silva et al., 2010). Para reduzir os efeitos do estresse pelo calor, podem ser utilizadas algumas estratégias de 
manejo ambiental, em que as instalações zootécnicas visem o controle de fatores climáticos, principalmente a temperatura ambiente, que leva ao desconforto térmico.

A avaliação da relação básica entre os animais e seu ambiente térmico começa com a zona de conforto térmico ou de termoneutralidade, a qual é determinada por uma faixa de temperatura ambiente efetiva dentro da qual o custo fisiológico é mínimo, a retenção da energia da dieta é máxima e o desempenho produtivo esperado é máximo (Baccari júnior et al., 1996).

A espécie caprina caracteriza-se pela suas adaptações às mais diversas condições de ambiente, verificando-se sua ocorrência em quase todas as regiões do mundo. Isto decorre da facilidade dos caprinos adaptarem-se às mais diferentes dietas, associadas à sua acentuada capacidade de aclimatação (Gomes et al., 2008; Silva et al., 2010). Esses ruminantes têm por característica serem seletivos, por isso caminham muito pela pastagem em busca das partes mais nutritivas das forrageiras. São animais de porte baixo, cabeça pequena, boca com lábios móveis e ágeis favorecendo a escolha de partes mais ricas dos vegetais como folhas e brotos (Van Soest, 1994).

Rigorosamente, todos os caprinos são originalmente exóticos, já que esses animais não existiam no Brasil, chegando com os colonizadores europeus a partir do século XVI (Gonçalves, 2012). Mas as espécies de animais domesticados trazidas para este país foram com o tempo se adaptando às condições locais, sofrendo modificações com o caminhar das sucessivas gerações, num processo de transformação. Depois de um longo período de tempo, resultaram em animais rústicos e bem aclimatados às difíceis condições do Semiárido. Mas a distância genética com as matrizes europeias, fez surgir novas raças, ou seja, as espécies são exóticas, mas as raças surgidas delas são naturalizadas. Hoje, estes animais (raças naturalizadas) apresentam menor porte e maior adaptação ao Semiárido, quando comparados com seus correspondentes europeus (raças exóticas) que lhes originaram.

A adaptabilidade dos animais é medida pela capacidade de produzir em determinadas condições climáticas, como na região Semiárida, sem perda do desempenho produtivo e sem alterações dos seus parâmetros fisiológicos normais (Gomes et al., 2008). No entanto, a introdução de animais exóticos nessas regiões pode melhorar a produtividade do rebanho, além de conseguirem a naturalização ou aclimatação regional. Portanto, a correta identificação dos fatores que influem na vida produtiva do animal, tais como o estresse imposto pelas flutuações estacionais do meio ambiente, permitem ajustes nas práticas de manejo dos sistemas de produção, possibilitando dar-lhes sustentabilidade e viabilidade econômica. Desta forma, o conhecimento das variáveis climáticas, sua interação com os animais e as respostas comportamentais, fisiológicas e produtivas são preponderantes na adequação do sistema de produção aos objetivos da atividade.

\section{Características fisiológicas}

A produtividade ou mesmo a sobrevivência animal, depende principalmente de sua capacidade em manter a temperatura corporal dentro de certos limites. Este processo denominase homeotermia, ou seja, a manutenção da temperatura corporal em níveis constantes, independentemente de variações da temperatura ambiente (Johnson, 1987).

Parâmetros como frequência respiratória, frequência cardíaca, temperatura corporal, temperatura retal, entre outros são comumentes utilizados para medir o estresse térmico dos animais (Magalhães et al., 2001, Azevedo et al., 2008; Silva et al., 2011; Furtado et al., 2012; Cattelam \& Vale, 2013; Mousinho et al., 2014).

Segundo McDowell (1972), o impacto do calor sobre as variáveis fisiológicas de vacas leiteiras resulta em um aumento de 194\% na frequência respiratória e $3,3 \%$ na temperatura retal, com alterações de 32 para 94 resp. min $^{-1}$ e de 38,6 para $39,9{ }^{\circ} \mathrm{C}$, respectivamente. A frequência respiratória alta pode ser uma estratégia eficiente de perder calor por curtos períodos, mas caso mantida por várias horas poderá resultar em sérios problemas para os animais. A respiração acelerada e contínua pode interferir na ingestão de alimentos e ruminação, adicionar calor endógeno a partir da atividade muscular e desviar a energia que poderia ser utilizada em outros processos metabólicos e produtivos. $\mathrm{O}$ incremento $\mathrm{da}$ atividade respiratória se constitui no primeiro sintoma visível da resposta ao estresse térmico quando o animal é submetido a temperaturas elevadas (McDowell, 1974). 
Arruda \& Pant (1985) estudando a frequência respiratória em caprinos pretos (raça Canindé) e brancos (raça Marota) de diferentes idades, observaram maior frequência respiratória no período da tarde $\left(33,4\right.$ resp. $\left.\mathrm{min}^{-1}\right)$ e os caprinos de pelagem preta $\left(27,3\right.$ resp. $\left.\mathrm{min}^{-1}\right)$ apresentaram maior frequência respiratória que os brancos $\left(24,4\right.$ resp. $\left.\mathrm{min}^{-1}\right)$. Os animais com pelagem escura tendem a apresentar uma temperatura do pelame mais elevada, devido a maior dificuldade de perder calor pela forma sensível. Em consequência, ocorre o aumento da perda de calor pela sudorese e da frequência respiratória. $\mathrm{O}$ aumento da frequência respiratória pode levar a uma taquipnéia prolongada causando redução na pressão sanguínea de $\mathrm{CO}_{2}$, além de sensível acréscimo no calor armazenado nos tecidos devido ao trabalho acelerado dos músculos respiratórios (Silva \& Starling, 2003). Nos casos de temperaturas extremas e contínuas, o animal, em consequência da hiperventilação, poderá entrar em um quadro de alcalose respiratória e morte.

Em situação de termoneutralidade, a frequência respiratória de caprinos apresenta um valor médio de 25 resp. min ${ }^{-1}$ (Dukes \& Swenson, 1996), podendo esse valor ser influenciado pelo trabalho muscular, temperatura ambiente, ingestão de alimentos, estado fisiológico, idade, tamanho do animal (Silva et al., 2005), sexo e estação do ano (Ogebe et al., 1996). Brasil et al. (2000) trabalhando com caprinos em condições de termoneutralidade e sob estresse térmico, verificaram que há uma variação da frequência respiratória com relação ao período do dia, sendo no turno da tarde superior ao turno da manhã.

De acordo com Radostits et al. (2002) um aumento elevado da temperatura ambiente pode dobrar a frequência respiratória normal dos animais, pois os mecanismos termorregulatórios acionados aumentam a perda de calor na forma latente, na tentativa de manter a temperatura corporal dentro dos limites normais, evitando a hipertermia. Em ovinos, Silanikove (2000) concluiu que a frequência respiratória pode quantificar a severidade do estresse térmico em ruminantes, em que a frequência respiratória de 40 a 60,60 a 80 e 80 a 120 resp. $m^{-1}$ caracterizam estresse baixo, médio a alto e alto, respectivamente. Acima de 200 resp. $\min ^{-1}$ o estresse seria severo. Em geral, para a espécie caprina em condições de conforto térmico a frequência cardíaca varia entre 70 a 90 bat. $\mathrm{min}^{-1}$ (Kelly, 1976), podendo ser influenciada pela espécie, raça, idade, trabalho muscular e temperatura ambiente (Kolb, 1980).

A vaso dilatação periférica é um dos mecanismos utilizados pelos animais para manterem a homeotermia, aumentando o fluxo sanguíneo para a superfície corporal e assim, aumentando a temperatura da superfície do animal e resfriando seu interior (Chemineau, 1993). Segundo Habeeb et al. (1992), o redirecionamento do fluxo sanguíneo e a vasodilatação facilitam a dissipação de calor por mecanismos não evaporativos (condução, convecção e radiação). Entretanto, a eficácia desses mecanismos depende do gradiente térmico entre o corpo do animal e o ambiente. Quando há um gradiente aceitável o excesso de calor corporal é dissipado do corpo aquecido para o meio mais frio, caso contrário, o animal tem que utilizar mecanismos evaporativos como a frequência respiratória e/ou a sudorese (Souza, 2003). A temperatura corporal é o resultado do equilíbrio entre a energia térmica produzida somada com a energia térmica ganha pelo ambiente e a energia térmica dissipada (Legates et al., 1991). Animais que são normalmente ativos durante o dia, variam menos sua temperatura corporal pela manhã em relação ao período da tarde (Anderson, 1988). Sob estresse térmico, notadamente no período da tarde, esta variação pode ser muito marcante, evidenciando uma hipertermia neste período do dia, (Arruda \& Pant, 1985). Já a temperatura retal é aumentada quando o animal está estocando calor e se este calor não é dissipado, o estresse térmico manifesta-se. Lima (1983), trabalhando com caprinos da raça Moxotó, no Semiárido Paraibano, observou efeito para os diferentes turnos, onde as fêmeas apresentaram um valor máximo de $38,8{ }^{\circ} \mathrm{C}$ no período da manhã e de $39,30{ }^{\circ} \mathrm{C}$ no período da tarde, enquanto os machos apresentaram um valor de $38,10^{\circ} \mathrm{C}$ pela manhã e $39,50{ }^{\circ} \mathrm{C}$ à tarde. Hopkins et al. (1978) afirmaram que valores de temperatura retal próximos à temperatura corporal considerada normal para a espécie podem ser tomados como indicativo de adaptabilidade. De acordo com McDowell (1976), a elevação de $1{ }^{\circ} \mathrm{C}$ ou menos na temperatura retal é o bastante para reduzir o desempenho da maioria dos animais domésticos.

Arruda \& Pant (1984) trabalhando no Nordeste do Brasil, observaram elevação de 1,48 ${ }^{\circ} \mathrm{C}$ na temperatura retal de caprinos. Brasil et al., (2000) trabalhando com cabras Pardo-alpinas em lactação submetidas a estresse térmico verificou 
médias de temperatura retal mais elevadas à tarde $\left(39,97{ }^{\circ} \mathrm{C}\right)$ do que pela manhã $\left(39,10{ }^{\circ} \mathrm{C}\right)$. Todas essas avaliações são importantes para auxiliar o estabelecimento de padrões termorregulatórios de animais supostamente adaptados a regiões Semiáridas, além de contribuirem para a avaliação do equilíbrio térmico entre o animal e o ambiente.

Em elevados níveis de temperatura ambiente, a evaporação torna-se a principal via para a dissipação de energia térmica dos animais (Finch, 1985), a qual ocorre na superfície da epiderme, pela sudorese (Silva \& Starling, 2003), e no trato respiratório (Maia et al., 2005). Por outro lado, sob essas condições, a condução, a convecção e a radiação podem eventualmente tornar-se mecanismos de ganho de energia térmica, pois dependem diretamente da temperatura ambiente (Gebremedhin \& Binxin, 2001). A evaporação sobre uma epiderme coberta por pêlos não ocorre da mesma forma que em uma superfície lisa e exposta, pois, acima da epiderme existe uma camada de pelame à qual adiciona resistência à difusão do vapor. Sabe-se que pelames bem assentados e pouco densos possuem menor resistência à transferência de vapor que aqueles densos e espessos (Cena \& Monteith, 1975a), os quais possibilitam maior taxa de transferência de energia térmica resultante da sudorese que ocorre na superfície da epiderme para sua vizinhança, em razão da menor resistência à difusão do vapor (Cena \& Monteith, 1975b) e, consequentemente, adaptam-se melhor às elevadas temperaturas e ao excesso de radiação em ambiente tropical (Scheleger \& Turner, 1965). Animais com altas taxas de sudorese, aliados a um pelame com menor resistência à convecção e à difusão de vapor, além de uma epiderme altamente pigmentada (Silva et al., 2003) devem ser considerados bons animais para serem criados em baixas latitudes.

\section{Características do pelame}

Os caprinos alcançam o equilíbrio térmico em ambientes quentes aumentando a dissipação de calor por meio, principalmente, da termólise cutânea e da respiratória (Silva, 2000a).

$\mathrm{O}$ estresse térmico imposto pelo ambiente depende da carga térmica interna e de fatores que governam a troca de calor. Estes últimos são dependentes dos gradientes de temperatura e de pressão de vapor da atmosfera e da resistência ao fluxo de calor entre estes gradientes. A cor do pelame e suas características (espessura, número de fibras por área, diâmetro e comprimento do pêlo) podem afetar consideravelmente os mecanismos de troca térmica (McArthur, 1991; Silva, 1999). O pelame dos animais assume importância fundamental para as trocas térmicas entre o organismo e o ambiente. Nas regiões tropicais, a capa tem a função de isolamento térmico, termólise evaporativa e termorregulação. Dentre as características que mais interessam aos organismos nas regiões tropicais, destaca-se a capacidade de resistência à intensa radiação solar, qualidade muito importante para os animais em condições de pasto. Tal capacidade está diretamente relacionada com a presença de uma capa externa de pelame apropriado (Silva, 2000a).

Em regiões tropicais, a definição do tipo de pelame mais vantajoso para caprinos, primeiramente depende do sistema de criação, ou seja, se existe proteção contra a radiação solar. De modo geral, o tipo mais vantajoso de caprino seria aquele que apresenta uma capa de pelame branco, com pêlos bem assentados sobre uma epiderme altamente pigmentada. Em qualquer caso, o pelame deverá ser o menos espesso possível, com pêlos curtos, grossos e bem assentados. A transferência térmica pelo pelame depende do número de pêlos por unidade de área, do ângulo de inclinação dos pêlos em relação à epiderme, de seu diâmetro e do seu comprimento. $\mathrm{O}$ calor conduzido pelas fibras é maior do que o conduzido pelo ar. Deste modo, quanto maior o número de pêlos por unidade de área e quanto mais grossos forem os mesmos, tanto maior será a quantidade de energia térmica conduzida pela capa. A resistência térmica da capa pode ser maior pela presença de fibras finas e compridas (Silva, 2000b). Além da estrutura morfológica do pelame, uma alta refletância à radiação de ondas curtas, que confere capacidade de resistência à intensa radiação solar é uma qualidade muito importante para os animais mantidos em condições de pasto.

Os caprinos apresentam pelame pouco denso, formado por pêlos finos e compridos (Ligeiro et al., 2006; Aiura et al., 2010). A baixa densidade de pêlos pode ser um indicativo de maior adaptação ao ambiente tropical, permitindo maior movimentação do ar entre os pêlos, removendo o ar aprisionado no interior da capa do pelame. Porém, a densidade e o diâmetro dos pêlos afetam a perda de calor pela movimentação do ar (convecção forçada) dentro da camada de pêlos, 
situação que se torna o principal mecanismo de transferência de calor (Gebremedhin et al., 1983), além de diminuirem a resistência à transferência de calor por convecção livre, a qual é induzida por um gradiente térmico causado por uma diferença de densidade do ar no interior da capa e, por último, favorecem a difusão do vapor pela capa, evaporada na superfície da epiderme para a vizinhança (Cena \& Monteith, 1975b).

Entretanto, quanto maior o diâmetro, maior a condução molecular através dos pêlos e, portanto, maior a condutividade térmica. Assim, pelames constituídos por pêlos grossos seriam mais vantajosos em ambientes quentes que aqueles formados por pêlos finos. No entanto, o acréscimo na transmissão térmica pelo pelame que pode ser atribuído à condução ao longo dos pêlos não é tão significativo (Cena e Monteith, 1975b), de modo que a convecção livre e a troca radiativa entre os pêlos são os maiores responsáveis pela transferência de calor através do pelame na ausência de movimentação de ar. Caso contrário, a convecção forçada pode dominar este processo, dependendo do nível de movimentação e da posição que o vento atinge a superfície corporal do animal (Nóbrega et al., 2011).

Ligeiro et al. (2006) observaram que as médias da espessura da capa do pelame $(5,80$ $\mathrm{mm})$ e do comprimento médio dos pêlos $(28,47$ $\mathrm{mm})$ de cabras leiteiras foram superiores às registradas por Maia et al. (2003) ao estudarem vacas Holandesas e por Silva et al. (1988), ao estudarem vacas Jersey. Entretanto, as médias do diâmetro $(8,0 \mu \mathrm{m})$ e do número de pêlos por unidade de área (527 pêlos. $\mathrm{cm}^{-2}$ ) foram inferiores às obtidas por Maia et al. (2003) para os pelames preto e branco, em vacas Holandesas.

Em estudo de tolerância ao calor com cabras da raça Sirohi, Acharya et al. (1995) observaram que os animais com pelame mais comprido tiveram melhor proteção ao ganho térmico da radiação solar. Desse modo, as características morfológicas do pelame podem indicar a condição de aclimatização ou adaptação dos animais ao meio em que vivem.

Aiura et al. (2010) observaram que a raça Saanen (caracterizada por pêlos e epiderme brancos) apresentou pelame mais denso que a raça Pardo-alpina, conferindo maior proteção à radiação solar, ao mesmo tempo pêlos mais grossos e curtos (consequentemente mais eretos), implicando na facilitação das trocas térmicas com o ambiente. Acharya et al. (1995) relataram que cabras com pelame branca tiveram menor estresse térmico do que as marrons e as pretas. Os pelames de coloração branca apresentam menores coeficientes de absorção; no entanto, deve-se levar em conta que a transmitância da radiação solar é maior que nos escuros (Maia et al., 2005).

\section{Níveis hormonais}

Numerosos trabalhos têm demonstrado que o estresse térmico não só desencadeia alterações agudas e crônicas nas concentrações plasmáticas de cortisol e hormônios tireoidianos, como também pode acarretar alterações nas reações fisiológicas e comportamentais dos animais. Assim, temperaturas elevadas associadas a altas umidades do ar e radiação solar são os principais elementos climáticos estressantes que causam diminuição na taxa de crescimento, na produção de leite e nas falhas de reprodução, diminuindo o índice de fertilidade dos rebanhos. El-Nouty et al. (1984) mostraram valores normais das concentrações plasmáticas de cortisol em cabras lactantes asiáticas, variando de acordo com a semana de lactação, sendo crescentes do início até a $8^{\text {a }}$ semana $(2,85 \pm 0,47$ a $4,01 \pm 0,79 \mu \%)$ e decrescente da $9^{\mathrm{a}}$ à $14^{\mathrm{a}}$ semana $(3,88 \pm 0,72$ a $2,80 \pm 0,48 \mu \%)$. Concentrações plasmáticas de cortisol de cabras em lactação de uma raça indiana e seus cruzamentos foram observadas por Ludri \& Sarma (1985) durante diferentes meses do ano, os quais reportaram valores médios mais elevados no mês de maio $\left(35,4{ }^{\circ} \mathrm{C} ; 8,85 \pm 2,62\right.$ ng. $\mathrm{mL}^{-1}$ ), sugerindo que o estresse térmico pelo calor pode influir nas concentrações de cortisol no sangue.

Resultados da literatura sobre alterações nas concentrações plasmáticas de tiroxina $\left(\mathrm{T}_{4}\right)$ e triiodotironina $\left(\mathrm{T}_{3}\right)$ em diversas espécies domésticas, quando submetidas a estresse térmico, não têm sido bem definidos, sendo, muitas vezes, contraditórios (Vieira, 1995). Variações das temperaturas ambientais são responsáveis por diferentes concentrações hormonais em cabras. Baccari Júnior et al. (1996) não encontraram diferenças entre as concentrações plasmáticas de tiroxina em cabras leiteiras, quando submetidas a estresse de $38,4{ }^{\circ} \mathrm{C}$ em câmara bioclimática.

\section{Comportamento animal}

O estudo do comportamento animal é uma ponte entre os aspectos moleculares e fisiológicos 
da biologia e da ecologia. O comportamento é a ligação entre organismos e o ambiente, e entre o sistema nervoso e o ecossistema é uma das propriedades mais importantes da vida animal, pois tem um papel fundamental nas adaptações das funções biológicas. $\mathrm{O}$ comportamento representa a parte de um organismo pela qual ele interage com o ambiente (Snowdon, 1999).

Os padrões de comportamento social (em particular dos comportamentos sexual e parental) e a determinação de uma ou mais estratégias para o acasalamento e para cuidados com as crias estão ligados às condições ecológicas em que estes animais se encontram (disponibilidade e distribuição de recursos alimentares, condições climáticas, pressão de predadores, competição intra e interespecífica, dentre outros). Os ruminantes (bovinos, ovinos e caprinos) por serem animais gregários, quando são isolados do rebanho tornam-se estressados. $\mathrm{Na}$ verdade, embora a vida em grupo traga uma série de vantagens adaptativas (defesa contra predadores, facilidade para encontrar o parceiro sexual etc.), ela também traz o aumento na competição por recursos, principalmente quando escassos, resultando na apresentação de interações agressivas entre os animais do mesmo grupo ou rebanho (Costa \& Nascimento Júnior, 1986).

Os caprinos apresentam uma série de padrões de organização social, que definem como serão as interações entre grupos e entre animais do mesmo grupo, contribuindo para minimizar os efeitos negativos da competição. Além da observação da organização social destes animais, as principais observações devem ser realizadas a cerca da: utilização do espaço, hierarquia de dominância, liderança e disponibilidade de espaço, tamanho e composição dos grupos. Os animais ao se dispersarem no ambiente, não o fazem ao acaso, utilizam o espaço conforme a estrutura física e florística do ambiente, clima e comportamento social (Arnold \& Dudzinski, 1978). Quando os animais são criados de forma extensiva e pouco manejados, estes definem sua área de vida (local amplo no qual eles desenvolvem todas suas atividades). O espaço é utilizado de forma interativa, podendo apresentar várias dimensões (dependendo da disponibilidade dos recursos e da pressão ambiental) e subdivisões: área de descanso e área de alimentação. Quando qualquer uma dessas áreas é defendida, surge o chamado território, que pode ser de uso múltiplo (toda a área de vida) ou de descanso (área onde os animais acampam para descansar). Há ainda o espaço individual, que é a área onde o animal se encontra, compreendido pelos espaços: físico (utilizado para realizar movimentos básicos) e social (distância mínima que se estabelece entre um animal e os demais membros do grupo). Além da área de segurança individual ou zona de fuga, que define a distância de fuga (área na qual o animal se sente seguro diante de um estranho, dominante ou predador). Todavia, tais padrões de espaçamento não são suficientes para a neutralização ou diminuição da agressividade entre animais que estão competindo por algum recurso. Há outro mecanismo de controle social, que tem origem na familiaridade e na competição entre os animais, resultando na definição da liderança e da hierarquia de dominância, respectivamente. Os rebanhos raramente apresentam grupos sociais naturais, devido aos interesses do homem (sexo, peso, idade fisiológica, produção, entre outros). A dominância se estabelece nesses grupos pela competição, ou seja, ela é produto de interações agressivas entre os animais de um mesmo grupo ao competirem por um determinado recurso, definindo quem terá prioridade no acesso a comida, água, sombra etc. Os fatores que normalmente determinam a posição na hierarquia são o peso, a idade e a raça (Wagnon et al., 1966; Le Neindre, 1989), portanto, deve-se ter cautela na formação de lotes, sob pena de se manter certos animais em constante estresse social (Costa \& Cromberg, 2005).

Outro aspecto do comportamento social dos caprinos é a liderança, que geralmente resulta na atividade sincronizada dos animais. Há sempre um animal, denominado líder, que inicia o deslocamento ou as mudanças de atividade, quando é seguido pelos demais membros do grupo. Tal comportamento não envolve atividades agressivas, mas sua compreensão é útil para o manejo dos animais nas pastagens, principalmente durante a condução do rebanho para áreas de manejo. Nas condições de sistemas intensivos de produção é muito comum a formação de grandes grupos de animais (alta densidade), com a expectativa de aumentar a produtividade, mas isso pode acarretar efeitos negativos sobre a expressão do comportamento e o desempenho individual dos animais. Portanto, é importante que o grupo seja estável em sua composição, para que a hierarquia social previamente estabelecida não seja alterada, provocando diminuição na produção e no bem estar animal. O tamanho ideal de um grupo, para 
a manutenção da ordem social é menor em condições de criação intensiva do que em extensiva (Costa \& Silva, 2007). Outro aspecto importante é a prática de homogeneização de grupos com relação ao sexo, idade, peso, com intuito de facilitar o manejo. Indivíduos isolados do rebanho tornam-se estressados, com exceção de fêmeas próximas ao parto, que se isolam para parir (Hötzel \& Machado Filho, 2004).

Os sistemas de acasalamento são definidos no sentido de buscar a compreensão da filogênese e ontogênese do padrão comportamental de uma dada espécie ou população no que se refere às estratégias de acasalamento observadas no grupo. Em ruminantes, este sistema é descrito como poligínico, quando um macho se acasala com muitas fêmeas, enquanto cada fêmea se acasala com um único macho (Phillips, 1993), há competição entre machos, sendo que as fêmeas providenciam o maior investimento parental.

A modulação do comportamento alimentar $\mathrm{e}$ espacial constitui-se em um dos meios mais efetivos por meio dos quais os animais adaptamse a diferentes fatores ambientais, na busca da satisfação de suas necessidades e da realização de suas funções vitais. Os ruminantes desenvolveram estratégias de alimentação ou mecanismos para aperfeiçoar a utilização do tempo na busca por alimento na pastagem, o que se denomina de comportamento ingestivo (Carvalho et al., 1999). Esta habilidade constituise em ferramenta potencialmente importante na busca da melhoria de sistemas de produção, podendo indicar métodos potenciais de melhoramento da produtividade animal por meio da utilização de diversas modalidades de manejo (Ray \& Roubicek, 1971).

\section{Considerações Finais}

A maioria da criação de cabras no Nordeste se concentra em regiões Semiáridas. Apesar de estes animais apresentarem grande adaptabilidade a ambientes quentes é importante salientar que o ambiente térmico, principalmente em condições semiáridas, é bastante complexo, limitando sensivelmente a termorregulação, pois a alteração de qualquer característica ambiental (radiação, velocidade do vento, umidade e a temperatura do ar) pode interferir no equilíbrio térmico animal. Portanto, é necessário que o fator climático seja levado sempre em consideração, uma vez que as condições climáticas da região Semiárida (região que corresponde a mais de $50 \%$ da área do
Nordeste brasileiro) se apresentam como estressantes, principalmente pelas altas temperaturas diurnas. E que esta atividade possa ser alavancada pela identificação de animais (raças) adaptados, bem como possa ser estabelecido uma zona de conforto para os animais em condições climáticas do semiárido.

\section{Referências Bibliográficas}

Abi Saab, S. \& Sleiman, F. T. (1995). Physiological responses to stress of filial crosses compared to local Awassi sheep. Small Ruminant Research, 16, 55-59.

Acharya, R. M., Gupta, U. D., Sehgal, J. P. \& Singh, M. (1995). Coat characteristics of goats in relation to heat tolerance in the hot tropics. Small Ruminant Research, 18, 245248.

Aiura, A. L. O., Aiura, F. S. \& Silva , R. G. (2010). Respostas termorreguladoras de cabras Saanen e Pardo Alpina em ambiente tropical. Archivos de Zootecnia, 59, 605-608.

Anderson, B. E. (1988). Regulação da temperatura e fisiologia ambiental. In: Dukes, H. H., Swenson, M. J. Fisiologia dos animais domésticos. 10. ed. Rio de Janeiro: Guanabara Koogan, p.623-629.

Arnold, G. W. \& Dudzinski, M. L. (1978). Ethology of free-ranging domestic animals. New York: Elsevier, 197p.

Arruda, F. A. V. \& Pant, K. P. (1985). Frequência respiratória em caprinos pretos e brancos de diferentes idades. Pesquisa Agropecuária Brasileira, 20, 1351-1354.

Arruda, F. A. V. \& Pant, K. P. (1984). Tolerância ao calor de caprinos e ovinos sem lã em Sobral. Pesquisa Agropecuária Brasileira, 19, 379-385.

Azevedo, D. M. M. R., Alves, A. A., Feitosa, F. S., Magalhães, J. A. \& Malhado, C. H. M. (2008). Adaptabilidade de bovinos da raça PéDuro às condições climáticas do semiárido do estado do Piauí. Archivos de Zootecnia, 220, 513-523.

Baccari Júnior, F., Gonçalves, H. C., Muniz, L. M. R., Polastre, R. \& Head, H. H. (1996). Milk production, serum concentrations of thyroxine and some physiological responses of Saanen-Native goats during thermal stress. Veterinária e Zootecnia, 8, 9-14. 
Brasil, L. H. A., Wechessler, F. S., Bacarri Júnior, F., Gonçalves, H. C. \& Bonassi, I. A. (2000). Efeito do estresse térmico sobre a produção, composição química do leite e respostas termorreguladoras de cabras da raça Alpina. Revista Brasileira de Zootecnia, 29, 1632-1641.

Broom, D. M. (1991). Animal welfare: concepts and measurement. Journal of Animal Science, 69, 4167-4175.

Broom, D. M. \& Fraser, A. F. (2007). Domestic animal behaviour and welfare. 4. ed. Wallingford: CAB International, 438p.

Carvalho, P. C. F., Prache, S., Roguet, C. \& Louault, F. (1999). Defoliation process by ewes of reproductive compared to vegetative swards. In: International Symposium on the Nutrition of Herbivores, 5. San Antonio. Proceedings... San Antonio: [s.n.].

Cattelam, J. \& Vale, M. M. (2013). Estresse térmico em bovinos. Revista Portuguesa de Ciências Veterinárias, 108, 96-102.

Cena, K. \& Monteith, J. L. (1975a). Transfer processes in animal coats. II. Conduction and convection. Procedure Royal Society, 188, 395-411.

Cena, K. \& Monteith, J. L. (1975b) Transfer processes in animal coats. III. Water vapor diffusion. Procedure Royal Society, 188, 413423.

Chemineau, P. (1993). Medio ambiente y reproducción animal. World Animal Review. Disponível em: <http://www.fao.org/DOCREP/V1650T/v165 0T04.htm>. Acessado em: 1 jan. 2016.

Costa, M. J. R. P. \& Cromberg, V. U. (2005). Alguns aspectos a serem considerados para melhorar o bem estar de animais em sistema de pastejo rotacionado. In: Peixoto, A. M., Moura, J. C., Faria, V. C. (Org.). Fundamentos do Pastejo Rotacionado. Piracicaba: FEALQ, .273-296.

Costa, M. J. R. P. \& Silva, E. V. C. (2007). Aspectos básicos do comportamento social de bovinos. Revista Brasileira de Reprodução Animal, 31, 172-176.

Costa, M. J. R. P. \& Nascimento Júnior, A. F. (1986). Estresse e comportamento. In: Semana de Zootecnia, 9., Pirassununga. Anais... Pirassununga: FMVZ/USP, p.65-72.
Cruz, V. F., Pereira, A. \& Silva, F. C. (2004). Monitorização de instalações pecuárias tendo em vista o bem estar animal. In: Congresso Luso-Brasileiro de Tecnologias de Informação e Comunicação na Agropecuária, 1., Santarém. Anais... Santarém: AGRI-TIC.

Dukes, H. H. \& Swenson, H. J. (1996). Fisiologia dos animais domésticos. 11.ed. Rio de Janeiro: Guanabara Koogan, 856p.

El-Nouty, F. D., Hassan, A., Samak, M. A., Mekkawy, M. Y., Salem, M. H. \& Nouty, F. D. (1984). Cortisol concentrations, leucocytes distribution, packed cell volumes, haemoglobin and serum protein during lactation in Egyptian Baladi goats. Indian Journal of Dairy Science, 37, 193-198.

FAWC. Farm animal welfare council. Five Freedoms: London, 2008.

Finch, V. A. (1985). Comparison of nonevaporative heat transfer in different cattle breeds. Australian Journal of Agricultural Research, 36,497-508.

Furtado, D. A., Peixoto, A. P., Nascimento, J. W. B. \& Regis, J. E. F. (2012) Environmental comfort in constructions for Sindi and Guzera calves in the agreste region of the state of Paraiba. Engenharia Agrícola, 32, 1-9.

Gabriel Filho, L. R. A., Pereira, D. F., Barato, F. F. \& Magalhães, M. M. (2011). Method of numerical correction of errors occasioned by delay of records during the monitoring of environmental variables of interest for animal production. Engenharia Agrícola, 31, 835846.

Gebremedhin, K. G. \& Binxin, W. U. (2001). A model of evaporative cooling of wet skin surface and fur layer. Journal of Thermal Biology, 26, 537-545.

Gebremedhin, K. G; Porter, W. P. \& Cramer, C. O. (1983). Quantitative analysis of the heat exchange through the fur layer of Holstein calves. Transactions of the ASAE, p.188-193.

Gomes, C. A. V., Furtado, D. A., Medeiros, A. N., Silva, D. S., Pimenta Filho, E. C. \& Lima Júnior, V. (2008). Efeito do ambiente térmico e níveis de suplementação nos parâmetros fisiológicos de caprinos Moxotó. Revista Brasileira de Engenharia Agrícola $e$ Ambiental, 12, 213-219. 
Gonçalves, O. J. (2012). Entre nativos e exóticos: a mestiçagem na construção de uma nova identidade na caprinovinocultura dos sertões. Revista IDEAS, 5, 89-117.

Habeeb, A. L. M., Maray, I. F. M. \& Kamal, T. H. (1992). Farm animals and the environment. Cambridge: Cab, 428p.

Hopkins, P. S., Knights, G. I. \& Le Feuvre, A. S. (1978). Studies of the environmental physiology of tropical Merinos. Australian Journal Agriculture Research, 29,161-171.

Hötzel, M. J. \& Machado Filho, L. C. P. (2004). Bem estar animal na agricultura do século XXI. Revista de Etologia, 6, 3-15.

Johnson, H. D. (1987). Bioclimatology and the adaptation of livestock. Amsterdam: Elsevier, $279 \mathrm{p}$.

Kelly, W. R. (1976). Diagnóstico clínico veterinário. 2. ed. Barcelona: Continental. 444p.

Kolb, E. (1980). Fisiologia veterinária. 4. ed. Rio de Janeiro: Guanabara Koogan. p.293294.

Leeb, C., Main, D. C. J., Whay, H. R. \& Webster, A. J. F. (2004). Bristol welfare assurance programme: Cattle Assessment. University of Bristol, $\quad 17 \mathrm{p} . \quad$ Disponível em: http://www.vetschool.bris.ac.uk/animalwelfar e/. Acesso em: 07 out. 2012.

Legates, J. E., Farthing, B. R., Casady, R. B. \& Barrada, M. S. (1991). Body temperature and respiratory rate of lactating dairy cattle under field and chamber conditions. Journal of Dairy Science, 74, 2491-2500.

Le Neindre, P. (1989). Influence of rearing conditions and breed on social behavior and activity of cattle in novel environments. Applied Animal Behaviour Science, 23, 129140.

Ligeiro, E. C., Maia, A. S. C; Silva, R. G. \& Loureiro, C. M. B. (2006). Perda de calor por evaporação cutânea associada às características morfológicas do pelame de cabras leiteiras criadas em ambiente tropical. Revista Brasileira de Zootecnia, 35, 544-549.

Lima, M. S. 1983. Correlação da temperatura corporal e volume globular de caprinos (Capra hircus L.) normais da raça Moxotó. 68 f. Dissertação (Mestrado) - Universidade Federal Rural de Pernambuco, Recife.
Ludri, R. S. \& Sarma, P. V. (1985). Cortisol concentrations in the blood plasma of lactating Beetal goats and their crosses. The Indian Journal of Animal Sciences, 55, 505508.

Lyons, D. M. (1989). Individual differences in temperament of dairy goats and the inhibition of milk ejection. Applied Animal Behaviour Science, 22, 269-282.

Magalhães, J. A., Costa, N. L., Pereira, R.G.A. \& Townsend, C.R. (2001). Desempenho produtivo e reações fisiológicas de ovinos deslanados mantidos sob seringal (Havea brasiliensis). Revista Cientifica de Produção Animal, 3, 77-82.

Maia, A. S. C., Silva, R. G. \& Bertipaglia, E. C. A. (2003). Características do pelame de vacas Holandesas em ambiente tropical: Um estudo genético e adaptativo. Revista Brasileira de Zootecnia, 32, 843-853.

Maia, A. S. C; Silva, R. G. \& Battiston, C. M. (2005). Sensible and latent heat loss from the body surface of Holstein cows in a tropical environment. International Journal of Biometeorology, 50, 17-22.

McArthur, A. J. (1991). Thermal radiation exchange, convection and the storage of latent heat in animal coats. Agricultural and Forest Meteorology, .53, 325-336.

McDowell, R. G. (1972). Improvement of livestock production in warm climates. San Francisco: Freeman and Company, 711p.

McDowell, R. E. (1974). Bases biológicas de la producción animal em zonas tropicales. 1. ed. Zaragoza: Acribia, 692p.

McDowell, R. E., Hooven, N. W. \& Camoens, J. K. (1976). Effects of climate on performance of Holsteins in first lactation. Journal of Dairy Science, 59, 965-973.

McInerney, J. P. (2004). Animal welfare, economics and policy - report on a study undertaken or the Farm \& Animal Health Economics Division of Defra. London.

Moberg, G. P. (1999). When does stress become distress? Laboratory animals, 28, 22-26.

Monty Junior, D. E., Kelly, L. M. \& Rice, W. R. (1991). Acclimatization of St Croix, Karakul and Rambouillet sheep to intense and dry summer heat. Small Ruminant Research, 4, 379-392. 
Mousinho, L. R. B., Campelo, J. E. G., Sousa Júnior, S. C., Azevêdo, D. M. M. R., Leal, T. M. \& Moura, R. M. A. S.. (2014). Respostas fisiológicas de cabras Anglonubianas a condições ambientais com temperatura elevada. Revista Brasileira de Saúde e Produção Animal, 15, 160-171.

Nóbrega, G. H., Silva, E. M. N., Souza, B. B. \& Mangueira, J. M. (2011). A produção animal sob a influência do ambiente nas condições do semiárido nordestino. Revista Verde de Agroecologia e Desenvolvimento Sustentável, 6, 67-73.

Ogebe, P. O., Ogunmodede, B. K. \& McDowell, L. R. (1996). Behavioral and physiological responses of Nigerian dwarf goats to seasonal changes of the humid tropics. Small Ruminant Research, 22, .213-217.

Oliveira, A. L. (2005). Avaliação da temperatura retal, frequência respiratória e taxa de sudação em cabras leiteiras. In: Reunião Anual da Sociedade Brasileira de Zootecnia, 42., 2005, Goiânia. Anais... Goiânia: Sociedade Brasileira de Zootecnia.

Phillips, C. J. C. (1993). Cattle behaviour. Ipswick, UK: Farming Press Books.

Radostits, O. M., Gay, C. C., Blood, D. C. \& Hinchcliff, K. W. (2002). Clínica veterinária: um tratado de doenças dos bovinos, ovinos, suínos, caprinos e equinos. 9.ed. Rio de Janeiro: Guanabara Koogan, 1736p.

Ray, D. E. \& Roubicek, C. B. (1971). Behavior of feedlot cattle during two seasons. Journal of Animal Science, 33,72-76.

Santos, F. C. B., Souza, B. B., Alfaro, C. E. P., César, M. F., Pimenta Filho, E. C., Acosta, A. A. A. \& Santos, J. R. S. (2005). Adaptabilidade de caprinos exóticos e naturalizados ao clima semiárido do nordeste brasileiro. Ciência e Agrotecnologia, 29, 142149.

Schleger, A. V. \& Turner, H. G. (1965). Sweating rates of cattle in the field and their reaction to diurnal and seasonal changes. Australian Journal of Agricultural Research, 16, 92-106.

Silanikove, N. (1992). Effects of water scarcity and hot environment on appetite and digestion in ruminants: a review. Livestock Production Science, 30, 175-194.
Silanikove, N. (2000). The physiological basis of adaptation in goats to harsh environments. Small Ruminant Research, 35, 181-193.

Silva, J. A. R., Araújo, A. A., Lourenço Júnior, J. B., Santos, N. F. A., Garcia, A. R. \& Nahúm, B. S. (2011). Conforto térmico de búfalas em sistema silvipastoril na Amazônia Oriental. Pesquisa Agropecuária Brasileira, 46, 13641371.

Silva, R. G. \& Starling, J. M. C. (2003). Evaporação cutânea e respiratória em ovinos sob altas temperaturas ambientes. Revista Brasileira de Zootecnia, 32,1956-1961.

Silva, R. G. (1988). Bioclimatologia e melhoramento do gado leiteiro. Revista do Gado Holandês, 5-12.

Silva, R. G. (1999). Estimativa do balanço térmico por radiação em vacas Holandesas expostas ao sol e á sombra em ambiente tropical. Revista Brasileira de Zootecnia, 28, 1403-1411.

Silva, R. G. (2000a). Introdução à bioclimatologia animal. São Paulo: Ed. Nobel/FAPESP, 286p.

Silva, R. G. (2000b). Um modelo para a determinação do equilíbrio térmico de bovinos em ambientes tropicais. Revista Brasileira de Zootecnia, 29, 1244-1252.

Silva, R. G., Arantes Neto, J. G. \& Holtz-Filho, S. V. (1988). Genetic aspects of the variation of the sweating rate and coat characteristics of Jersey cattle. Brazilian Journal of Genetics, 11, 335-347.

Silva, R. G., Lascala Junior, N. \& Tonhati, H. (2003). Radiative properties of the body surface of cattle and others animals. Transaction of ASAE, 46, 913-918.

Silva, R. G., Souza, B. B. \& Alfaro, C. E. P. (2005). Efeito das épocas do ano e de turno sobre os parâmetros fisiológicos e seminais de caprinos no semi-árido paraibano. Agropecuária Científica no Semiárido, 1, 714.

Silva, E. M. N., Souza, B. B., Souza, O. B., Silva, G. A. \& Freitas, M. M. S. de. (2010). Avaliação da adaptabilidade de caprinos ao semiárido através de parâmetros fisiológicos e estruturas do tegumento. Revista Caatinga, 23, 142-148. 
Snowdon, C.T. (1999). O significado da pesquisa em Comportamento Animal. Estudos de Psicologia, 4, 365-373.

Souza, B. B. (2003). Avaliação da adaptabilidade de ovinos de diferentes genótipos às condições climáticas do semiárido através de respostas fisiológicas e gradientes térmicos. In: Congresso Pernambucano de Medicina Veterinária, 5. Recife. Anais... Recife: [s.n.], 281-282.

Van Soest, P. J. (1994). Nutritional ecology of the ruminant. 2. ed. Ithaca: Cornell University Press, 476p.

Vieira, R. J. (1995). Respostas fisiológicas e hormonais de novilhas bubalinas submetidas a estresse térmico. $152 \mathrm{f}$. Tese (Doutorado em Medicina Veterinária) - Universidade Estadual Paulista, Botucatu.

Wander, A. E. \& Martins, E. C. (2008). Viabilidade econômica da caprinocultura leiteira. Uberaba: Agropecuária Tropical, 6p. (Anuário Brasileiro de Caprinos e Ovinos). Disponível em: $<$ http://ainfo.cnptia.embrapa.br/digital/bitstrea m/item/34396/1/ABCOWander.pdf $>$. Acesso em: 2 de jan. 2016.

Wagnon, K. A., Loy, R. G., Rollins, W. C. \& Carroll, F. D. (1966). Social dominance in a Herd of Angus, Hereford and Shorthorn cows. Animal Behaviour, 14, 474-479.

Recebido em Janeiro 4, 2016

Aceito em Fevereiro 8, 2016

License information: This is an open-access article distributed under the terms of the Creative Commons Attribution License, which permits unrestricted use, distribution, and reproduction in any medium, provided the original work is properly cited 